\title{
Flame Spread over Fuel Soaked Sand in an Opposed Air Stream
}

\author{
TAKUJI SUZUKI and MASAAKI KAWAMATA \\ Department of Mechanical Engineering \\ Ibaraki University \\ Ibaraki, Japan
}

\section{TOSHISUKE HIRANO}

Department of Reaction Chemistry

University of Tokyo

Tokyo, Japan

\section{ABSTRACT}

Flame spread over kerosene soaked sand in a quiescent atmosphere and an opposed air stream has been examined, and the effects of the air stream on the flame spread mechanisms are discussed. The aspects of spreading flames, the flame spread rate, and the temperature distributions near leading $f l a m e$ edges were examined for various initial temperatures $T_{i}$ of kerosene soaked sand and free stream velocities $U$ of the opposed air stream. As U increases, the flame near its leading edge approaches the sand surface. The flame spread rate $V_{f}$ at $U=0$ increases considerably with $T_{i}$. As $U$ increases, $V_{f}$ decreases rapidly and then gradually decreases until. U becomes $275 \mathrm{~cm} / \mathrm{s}$ in the limits of present experiments. When $U$ exceeds $275 \mathrm{~cm} / \mathrm{s}$, the flame spread becomes unstable and $V_{f}$ decreases rapidiy. In the case of $\mathrm{U}=0$, the heat transfer from the flame zone to the unburned region ahead of the leading flame edge seems to depend largely on the flame radiation. On the other hand in the case of $\mathrm{U} 0$, the heat transfex to the unburned region seems to depend largely on the heat conduction through the sand layer. The stabilization of the leading flame edge associated with the aerodynamic structure of the reverse flow region is found to be necessary for the stable flame spread.

\section{INTRODUCTION}

When combustible liquids are spilled, most of them will soak into porous materials such as wood, soil or cloths. If they axe accidentally ignited, the flame will spread over the porous solid soaked with the spilled combustible liquid. For the prediction of the hazards in such a case, knowledge of flame spread mechanisms over porous solids soaked with combustible liquid seem to be indispensable. However, available data on the flame spread over the combustible porous solid are very few (1), (2), although the flame propagation through layered flammable mixture has been studied by many investigators (3)-(6). In a few previous studies, the flame spread over crude oil sludge has been examined (8), (9), however, little information is given on the dependence of flame spread on the solid or combustible liquid characteristics.

In the meantime, most of the studies on the flame spread over combustible liquid or solid have been concerned with the phenomena in a quiescent atmosphere. However, in most actual cases, fires have occurred in winds. As observed previously (7), the flame behavior in an air stream 
must be significantly affected by such a wind. Therefore, knowledge of the flame spread in the air stream is necessary for the hazard assessment of actual fires on the porous solid soaked with a combustible liquid at sub-flash temperature.

In the present study, therefore, the flame spread over kerosene soaked sand in a quiescent atmosphere and an opposed air stream have been examined in detail, and the effects of the air stream on the flame spread mechanisms are discussed.

\section{EXPERIMENTAL APPARATUS AND PROCEDURE}

A schematic diagram of the experimental apparatus is shown in Fig. 1 . A tray of $60 \mathrm{~cm}$ long, $12 \mathrm{~cm}$ wide, and $1 \mathrm{~cm}$ deep was used for the flame spread experiments. As discussed in our previous paper (9), the width of $12 \mathrm{~cm}$ would be sufficient for neglecting the quenching effect of side walls of the tray on flame spread phenomena, and the depth of 1 cm would be enough for observing typical aspects of the flame spreads over thick layers of combustible materials. The tray was placed in the temperature control bath. An aluminum flat plate was set to be flush with the brim of the tray. The leading edge of the flat plate was sharpened on the top surface, and the distance from leading edge of the flat plate to the brim of the tray was $30 \mathrm{~cm}$. Both the tray and the flat plate were set up in the test section of the wind tunnel with the outlet of $60 \mathrm{~cm} \times 45 \mathrm{~cm}$ cross section, where the air stream was uniform and its turbulence intensity was less than 1 in the experimental range of up to $600 \mathrm{~cm} / \mathrm{s}$.

Aspects of the flame spread over porous solids soaked with combustible liquids depend on the properties of the porous solids (2). However, when glass and lead beads soaked with kerosene were used as the combustible porous solids, the aspects of the flame spread were independent of the materials of porous solids, and the flame spread rate was almost constant in the range of bead diameter less than $0.05 \mathrm{~cm}$ (10). In the present experiments, therefore, the sand soaked with kerosene was used as a representative example of the combustible porous solids. The mean grain size of the sand sieved by using 60 -mesh and $100-$ mesh screens was $0.022 \mathrm{~cm}$. The density of the sand grains was $2.68 \mathrm{~g} / \mathrm{cm}^{3}$ and the pore volume of the sand was about $0.32 \mathrm{~cm}^{3} / \mathrm{g}$ (46 vol. ${ }^{\circ}$ ). Kerosene (flash point: about $50{ }^{\circ} \mathrm{C}$ ) was supplied to fill the pore volume of the sand with the fuel liquid.

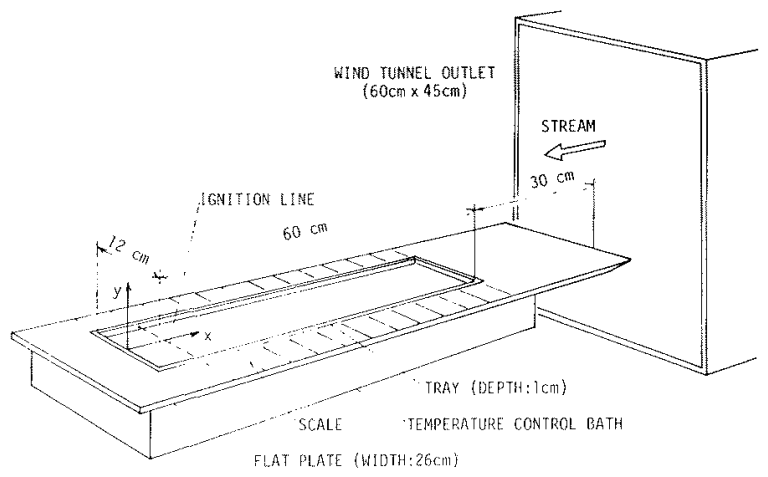

FIGURE 1 .

Experimental apparatus. 


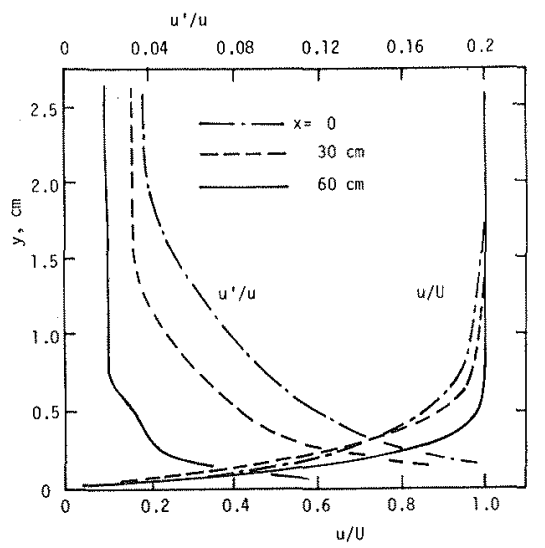

As the velocity distribution of the air stream over the surface of the fuel soaked sand is closely related to the mode of the flame spread, the profiles of mean velocity and turbulence intensity across the boundary layer over the sand surface were measured using a hot-wire anemometer. The measurements were conducted by setting up a tight, very thin polyethylene film over the tray. Typical examples of the profiles measured at three representative points are shown in Fig. 2, where $x$ is the distance from the end brim of the tray and $y$ the distance from the sand surface (Fig. 1), u the velocity parallel to the sand surface in the boundary layer, $u$ ' the root mean square of the velocity fluctuation, and $\mathrm{u}$ the free stream velocity. In a representative case of $x=30 \mathrm{~cm}$ and $\mathrm{y}=300$ $\mathrm{cm} / \mathrm{s}$, the velocity gradient ( $\partial \mathrm{u} / \partial \mathrm{y})$ at the sand surface is $1010 \mathrm{~s}^{-1}$ and the displacement thickness of the boundary layer is $0.23 \mathrm{~cm}$.

The tray was filled with the sand soaked with kerosene and its surface was finished to be flat by using a trowel. The initial sand temperature was controlled by adjusting the bath temperature to a predetermined value. The sand in the tray was ignited at $x=5 \mathrm{~cm}$ near the tray end brim by burning a $3-\mathrm{mm}$ diameter cotton string soaked with ethanol (Fig. 1 ). For the flame spread in an opposed air stream greater than $\mathrm{U}=200 \mathrm{~cm} / \mathrm{s}$, after igniting the sand in a stream at $U=150 \mathrm{~cm} / \mathrm{s}$, the stream velocity was increased to the predetermined value.

The aspects of spreading flames were examined by using a motor-driven $35 \mathrm{~mm}$ camera, and the movement of the leading flame edge was measured with a timer and the scale marked on the flat plate (Fig. 1).

The temperature distribution in the sand during flame spread was measured by using $3 \mathrm{C}-\mathrm{A}$ thermocouples (wire diam.: $0.01 \mathrm{~cm}$ ) installed at: $y=-0.2,-0.5$ and $-0.8 \mathrm{~cm}, x=30 \mathrm{~cm}$. The temperatures were recorded with a high-speed digital recorder.

\section{EXPERIMENTAL RESULTS AND DISCUSSION}

Aspects of Flame Spread

Typical aspects of the flame spreads over kerosene soaked sand in a quiescent atmosphere and an opposed air stream are shown on the photographs in Fig. 3. The flame size in the longitudinal direction (in $x$ 


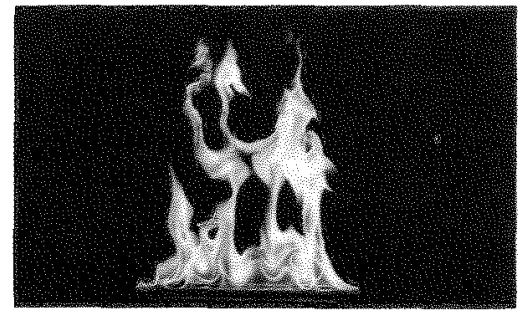

a. $\mathrm{U}=0$.

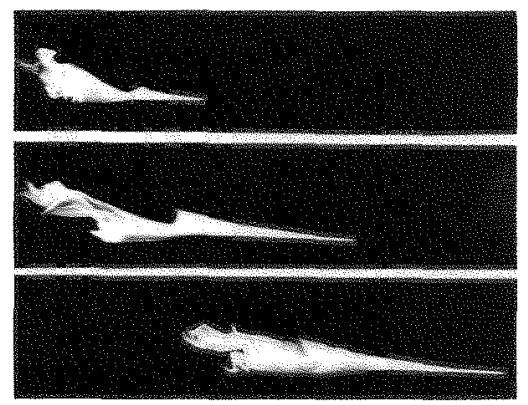

b. $\mathrm{U}=150 \mathrm{~cm} / \mathrm{s}$
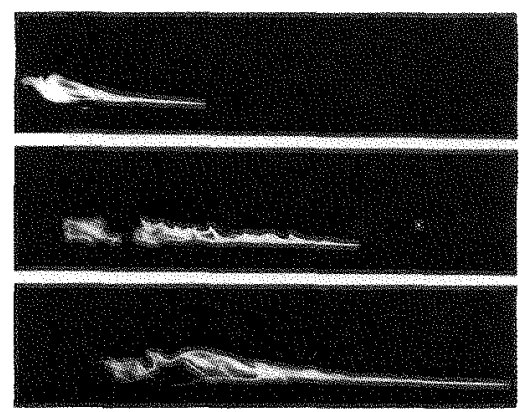

c. $\mathrm{U}=250 \mathrm{~cm} / \mathrm{s}$

\section{EIGURE 3}

Photographs representing typical

aspects of the flame spreads; $T_{i}=20^{\circ} \mathrm{C}$.

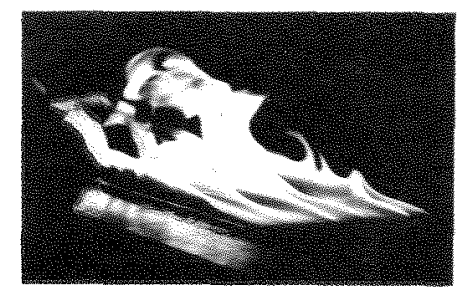

FIGURE 4 .

A photograph representing a typjcal. aspect of the flame spreading in an air stream; $T_{i}=20^{\circ} \mathrm{C}, \mathrm{U}=150 \mathrm{~cm} / \mathrm{s}$, $x_{1}=15 \mathrm{~cm}\left(x_{1}-1\right.$ ocation of the leading flame edge)!

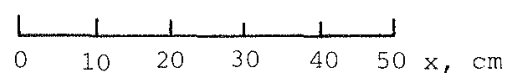

direction) is observed to increase as the flame spreads over the sand surface. However, the aspects near leading flame edge are almost. constant during each case of flame spread. As the free stream velocity u increases, the flame near its leading edge approaches the sand surface and the configuration of the flame far from the leading edge becomes more wavy. Such a flame spreading mode in the air stream is found to be much different from that observed in the quiescent atmosphere (U=0).

Figure 4 shows a typical aspect of the flame spreading in an air stream. A blue leading flame edge followed by a luminous yellow zone is observed, although the blue flame region is not seen clearly on the photograph in Fig. 4. In the luminous yellow zone behind the blue flame region, a few pair of longitudinal vortexes are formed. 
on the sand surface in front of the leading flame edge, a reverse flow region was found to be formed. The existence of the reverse flow region could be confirmed by observing the flow field visualized with naturally generated vapor mist in the stagnation region in front of the leading flame edge.

\section{Flame Spread Rate}

In Fig. 5, position-time $(x-t)$ diagrams representing the movements of the leading flame edges for typical cases are shown, where $t$ is the time from ignition. Except for a special case of unstable spread $(U=300 \mathrm{~cm} / \mathrm{s})$, each flame is found to spread at a constant rate, so that the spread rate $V_{f}$ can be easily determined from the $x-t$ diagram.

The variation of $V_{f}$ with the initial temperature $T_{i}$ of the kerosene soaked sand for the flame spread in a quiescent atmosphere ( $U=0)$ is shown in Fig. 6. The values of $V_{f}$ are almost the same as those for the crude oil sludge added 10 \% of n-hexane (8). $V_{E}$ increases considerably with $T_{i}$.

To explore the effects of the aix stream on the flame spread, variations of $V_{f}$ with $U$ were examined in detail for two representative initial temperatures of kerosene soaked sand. The results axe shown in Fig. 7. As $u$ increases, $V_{f}$ greatly decreases in the range of $U \ll 50 \mathrm{~cm} / \mathrm{s}$, and then gradually decreases until $U$ becomes $275 \mathrm{~cm} / \mathrm{s}$. The decreasing rate of $V_{f}$ with $U$ increases as $U$ approaches the cxitical value $U_{c}$ where $v_{f}$ becomes 0 . Although $V_{f}$ strongly depenas on $T_{i}, U_{C}$ is almost the same in both cases of $\mathrm{T}_{i}=20^{\circ} \mathrm{C}$ and $30^{\circ} \mathrm{C}$.

When $U$ is smallex than $275 \mathrm{~cm} / \mathrm{s}$, a stable flame spread with a constant spread rate can be observed as shown in Figs. 3-5. However, when $u$ is larger than $275 \mathrm{~cm} / \mathrm{s}$, the flame spread becomes unstable and the spread rate changes with the time as shown in Fig. 5. In the process of unstable flame spread, the blue leading flame edge fluctuates and so its configuration become jagged.

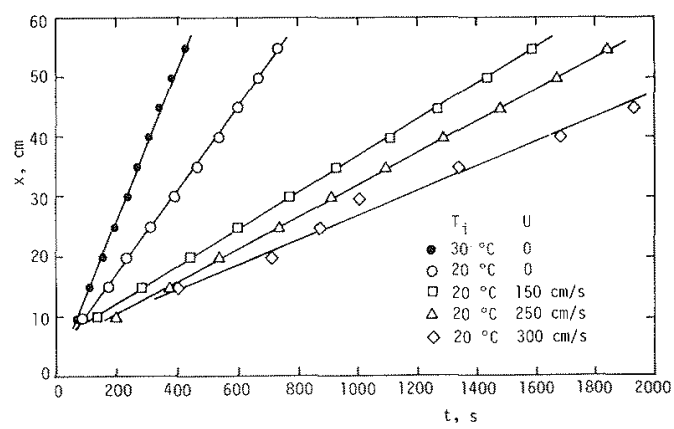

FIGURE 5 .

Position-time $(x-t)$ diagrams representing the movements of the leading flame edges.

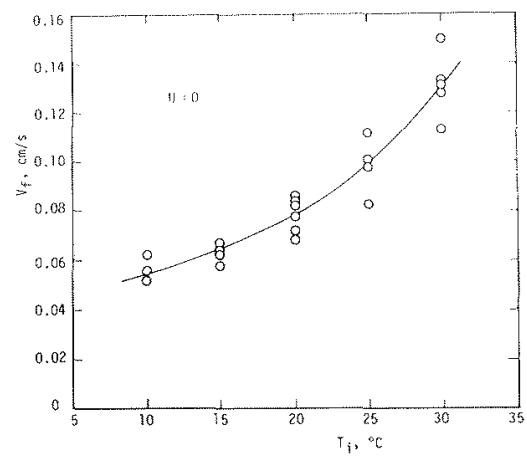

FIGURE 6.

Variation of the flame spread rate in a quiescent atmosphere with the initial temperature of fuel soaked sand. 

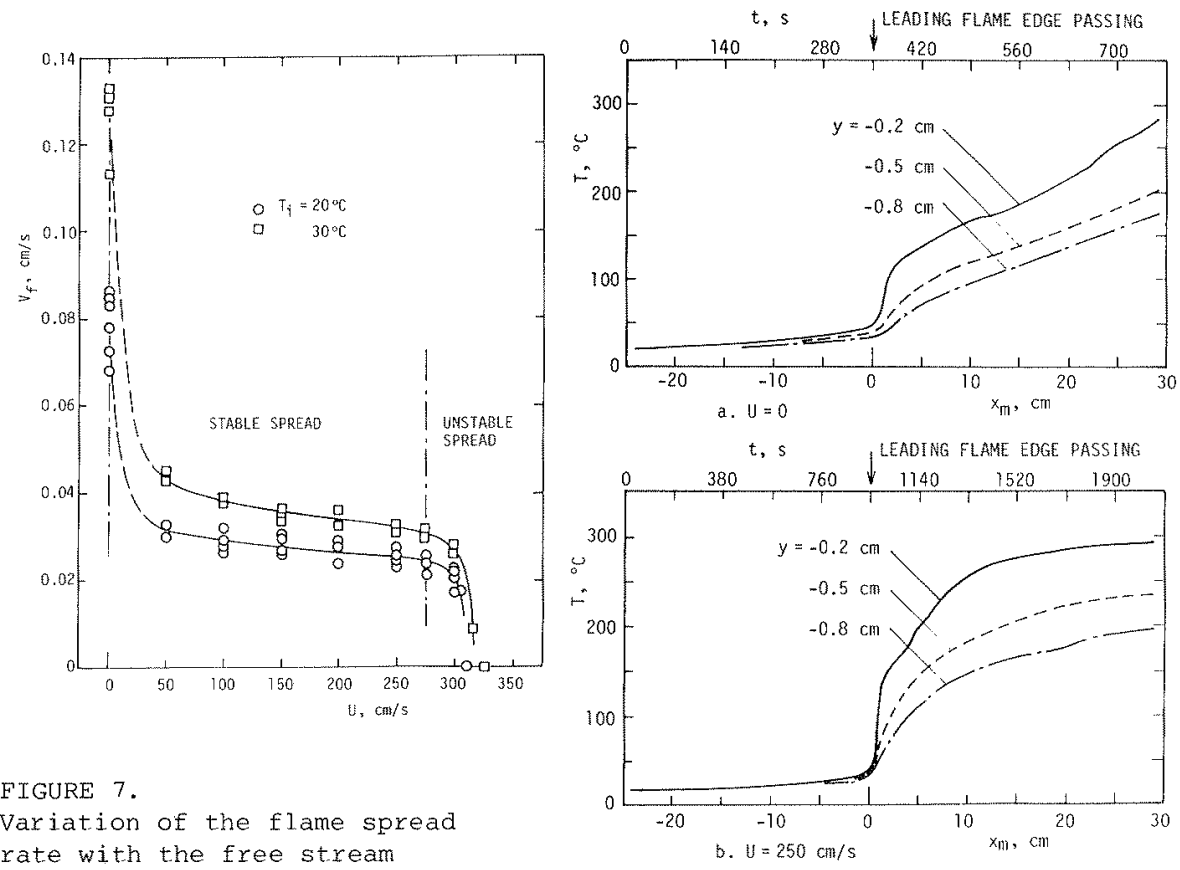

FIGURE 7

Variation of the flame spread rate with the free stream velocity for typical initial temperatures of fuel. soaked FIGURE 8.

Typical temperature distributions in the sand during flame spread based on the $\mathrm{T}-\mathrm{t}$. diagrams; $\mathrm{x}$-distance from the leading flame edge obtained by assuming constant flame spread, $T_{i}=20^{\circ} \mathrm{C}$.

Temperature Distribution in Fuel soaked Sand

Fig. 8 shows typical temperature distributions in the sand during stable flame spread, which is based on the temperature-time ( $x-t)$ diagrams recorded with the thermocouples installed in the centex of the tray at 25 cm from the ignition line. Since the flame near its leading edge can be assumed to spread with a constant spread rate without changing its configuration (Fig. 3 and 5 ), the temperature distribution ( $\mathrm{T}-\mathrm{x}_{\mathrm{m}}$ diagrams) in the sand can be derived directly from the T-t diagrams as shown in Fig. 8 , where $T$ is the temperature in fuel soaked sand and $x_{m}$ is the distance from the leading flame edge. From these temperature distributions, the heat. fluxes in the fuel soaked sand can be inferred. $T$ in the sand layer at a constant depth is found to increase as $x$ increases. $T$ increases gradually with $x_{m}$ in the region ahead of the leading flame edge, i.e., for $\mathrm{x}_{\mathrm{m}}<0$, and then increases rapidly in the region just behind the leading flame edge.

In the case of $\mathrm{y}=0$ and $\mathrm{x}_{\mathrm{m}}<0, \mathrm{~T}$ of $\mathrm{y}=-0.2 \mathrm{~cm}$ is much larger than that of $y=-0.5 \mathrm{~cm}$, that is, the temperature gradient $\partial \mathrm{T} / \partial \mathrm{y}$ in $\mathrm{y}$ direction is considerably large in the wide region ahead of the leading flame edge, and so considerable heat flux from the sand surface to its inside seems to exist. For example, at $\mathrm{x}_{\mathrm{m}}=-2 \mathrm{~cm}$ and $\mathrm{y}=-0.2 \mathrm{~cm}, \mathrm{~T}=40.9^{\circ} \mathrm{C}$ and $\partial \mathrm{T} / \partial \mathrm{y}$ is about. 
$18.7^{\circ} \mathrm{C} / \mathrm{cm}$. These facts indicate that the heat transfer from the flame zone to the unburned region ahead of the leading flame edge depends largely on the flame radiation which directly heats the surface of the unburned material.

On the other hand in the case of $\mathrm{U}=250 \mathrm{~cm} / \mathrm{s}$ and $\mathrm{x}<0$, T of $\mathrm{y}=-0.2 \mathrm{~cm}$ is almost the same as that of $y=-0.5 \mathrm{~cm}$, that is, $\mathrm{m}_{\mathrm{T}} \mathrm{\partial y}$ in the region ahead of the leading flame edge is very small. For example, at $x_{m}=-2 \mathrm{~cm}$ and $y=-0.2 \mathrm{~cm}, T=29.5^{\circ} \mathrm{C}$ and $\partial \mathrm{T} / \partial \mathrm{y}$ is about $2.3^{\circ} \mathrm{C} / \mathrm{cm}$. Therefore, the heat $f l u x$ by radiation to the sand surface seems to be very small. However, the temperature gradient $\partial \mathrm{T} / \partial \mathrm{x}\left(\mathrm{i} . \mathrm{e} ., \partial \mathrm{T} / \partial \mathrm{x}_{\mathrm{m}}\right.$ ) in $\mathrm{x}$ direction in the region just behind the leading flame edge is large, so that intense heat conduction from the high temperature region behind the leading flame edge to the unburned region ahead of it through the sand layer occurs. At $x_{m}=0.8 \mathrm{~cm}$ and $y=-0.2 \mathrm{~cm}, \partial \mathrm{T} / \partial \mathrm{x}_{\mathrm{m}}$ is $142^{\circ} \mathrm{C} / \mathrm{cm}$. These facts implies that the heat transfer from the flame zone to the unburned region ahead of the leading flame edge depends largely on the heat conduction through the sand layer. Such a mode of the heat transfer process in this case is found to be much different from that in the case of $\mathrm{U}=0$.

Effects of Air Stream on Flame Spread Mechanisms

For the flame spread over porous solids soaked with combustible liquids at sub-flash temperatures, preheating of the combustible material ahead of the leading flame edge is necessary. Therefore, the mode and the rate of the heat transfer from the flame zone to the unburned material characterize such a flame spread (8), (11).

It was shown that in the case of the flame spread in a quiescent atmosphere $(U=0)$, the sand surface at a certain distance far from the leading flame edge is preheated directly by radiation to a higher temperature close to the flash point (Fig. 8). In this case, accordingly, only a small amount of preheating must be needed in the region just ahead of the leading flame edge, which seems to occur by heat conduction through the sand layer and by heat convection through the gas phase. As aforementioned, therefore, the heat transfer by radiation from flame zone to the unburned region is supposed to be the dominant mode for the flame spread in a quiescent atmosphere. The flame spread rate in this case seems to increase considerably with $\mathrm{T}_{i}$, because the temperature difference between $T_{i}$ and the flash point decreases with $T_{i}$.

on the other hand in the case of the flame spread in an opposed air stream $(U>0)$, although the effects of the opposed air stream on the flame spreading mode are drastic, the stable flame spread can be observed in the wide range of U from $50 \mathrm{~cm} / \mathrm{s}$ to $275 \mathrm{~cm} / \mathrm{s}$ (Fig. 7). As inferred from the temperature distributions (Fig. 8), the heat transfer from the flame zone to the unburned region ahead of the leading flame edge depends largely on the heat conduction from the high temperature region behind the leading flame edge through the sand layer.

For the continuous, stable flame spread in an opposed air stream, the stabilization of the leading flame edge should be also necessary. In order to discuss such a flame stabilization mechanism, an illustration of the flow field in front of the leading flame edge and the aspect of the flame spreading in an air stream is shown in Fig. 9.

The visible flame zone was observed at some distance from the sand surface, the distance d of which at the leading flame edge was less than 


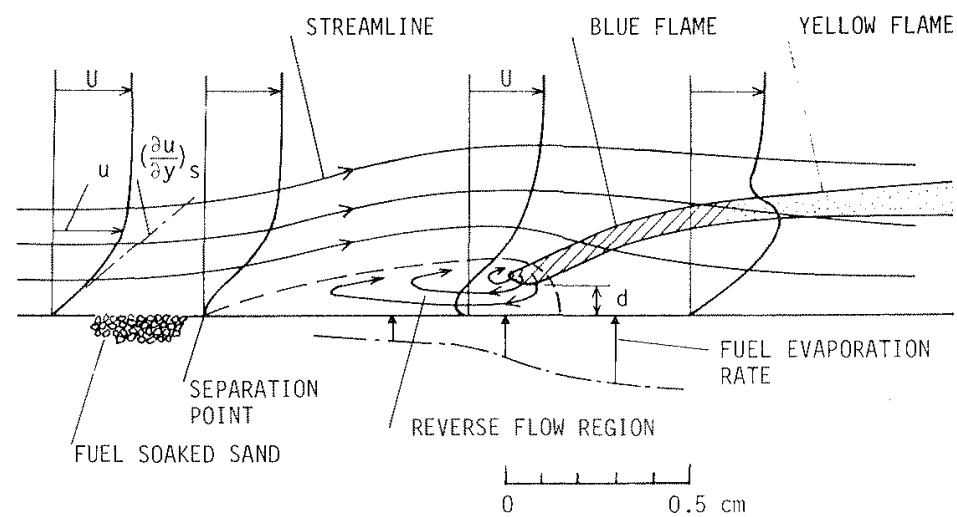

FIGURE 9. An illustration of the flow field in front of leading flame edge and the aspect of the flame front spreading in an air stream.

$0.1 \mathrm{~cm}$. The light intensity of the blue flame zone decreased with the distance from its leading edge, and then a yellow zone appeared on the fuel side of the blue flame zone. On the sand surface in front of the leading flame edge, the reverse flow region was observed, which must be formed with the interaction of the boundary layer and the reverse flow induced by the effect of the thermal expansion of gas due to the combustion at the leading flame edge. The streamlines shown in Fig. 9 were drawn on the basis of the previous results (12).

In the reverse flow region, a certain amount of heat and fuel vapor seem to be transferred by the convection induced in the thin gas layer on the sand surface. The transferred fuel vapor should be entrained into the main air flow outside of the reverse flow region to supply a fuel-air mixture to the blue flame zone. Such aerodynamic and thermal structures of the flow field in front of the leading flame edge seem to be essential for the stabilization of the leading flame edge and the spread rate of the flame spreading in the opposed air stream. Since d seems to be constant and nearly equal to quenching distance, the aspects of the reverse flow region is considered to depend mainly on the condition of upstream boundary layer. As discussed in previous papers (7), (13), the velocity gradient $(\partial u / \partial y)$ in $y$ direction, at the solid surface can be considered to be a representative value to express the velocity profile in front of the leading flame edge. From the results of the flame spread over a paper (13), it was shown that. $(\partial u / \partial y)$ near the leading flame edge increases slightly with increase of $U$, so that the aerodynamic structure near leading edge of the stable flame does not change largely. Even in the present case, similar depedency of the aerodynamic structure near leading flame edge on $U$ can be assumed. That is, (Ju/zy) near separation point ahead of the leading flame edge seems to increase slightly with increase of $U$ and so the aerodynamic structure of the reserve flow region might scarcely change. Therefore, it is supposed that the flame can spread stably in the opposed air stream and its spread rate gradually decreases in the wide range of $\mathrm{U}$ from $50 \mathrm{~cm} / \mathrm{s}$ to $275 \mathrm{~cm} / \mathrm{s}$ in both cases $\mathrm{T}=20^{\circ} \mathrm{C}$ and $30^{\circ} \mathrm{C}$ (Fig. 9). When ( $\partial u / \partial y)$ in upstream boundary layer approaches a critical value $(\partial u / \partial y)_{S c}$ at $U=U_{c}^{s}$, the leading flame edge becomes unstable, and then its 
spread rate decreases largely. These critical values (au/dy) and $u_{c}$ were almost independent of $\mathrm{T}_{i}$, and were about $1000 \mathrm{~s}^{-1}$ and $300 \mathrm{sc} / \mathrm{s}$, respectively.

Thus, it is found that not only the heat conduction to the unburned region through the sand layer, but also the stabilization of the leading flame edge associated with the aerodynamic structure ahead of the leading flame edge is necessary for the stable flame spread in an opposed air stream.

\section{CONCLUSIONS}

Flame spread over kerosene soaked sand in a quiescent atmosphere and an opposed air stream have been examined in detail, and the effects of the air stream on the flame spread mechanisms are discussed.

The mode of flame spread in an air stream is shown to be much different from that in a quiescent atmosphere. As the free stream velocity U of the opposed air stream increases, luminous yellow flame zone behind the leading flame edge approaches the sand surface.

The flame spread rate $V_{f}$ at $U=0$ is shown to increase considerably with the initial temperature ${ }^{F_{1}}$ of the kerosene soaked sand. As $U$ increases, $V_{f}$ decreases rapidly and then gradually decreases until U becomes $275 \mathrm{~cm} / \mathrm{s}$ within the limits of present experiments. When U exceeds 275 $\mathrm{cm} / \mathrm{s}$, the flame spread becomes unstable and $v_{f}$ rapidily decreases. The critical value of $U$ where $v_{f}$ becomes 0 is shown to be about $300 \mathrm{~cm} / \mathrm{s}$.

From the typical temperature distributions in the sand during flame spread, the dominant mode of heat transfer for flame spread are inferred, and the flame spread mechanisms are discussed. In the case of the flame spread in a quiescent atmosphere $(\mathrm{U}=0)$, the heat transfer to the unburned region ahead of the leading flame edge seems to depend laxgely on the intense radiation from the luminous yellow flame zone. On the other hand in the case of the flame spread in an opposed aix stream $(U>0)$, the heat transfer from the flame zone to the unburned region ahead of the leading flame edge is found to depend largely on the heat conduction from the high temperature region through the sand layer. For the stable flame spread in an opposed air stream, the stabilization of the leading flame edge associated with the aerodynamic structure of the reverse flow region in front of the leading flame edge is also needed.

The reverse flow region is supposed to be formed with the interaction of the boundary layer and the reverse flow induced by the effect of the thermal expansion of gas due to combustion. In the reverse flow region, a certain amount of heat and fuel vapor should be transferred by the convection to establish stable leading flame edge. It is discussed that the aerodynamic structure of the reverse flow region might scarcely change with increase of $U$, so that $V_{f}$ gradually decreases with $U$ in the wide range of the stable flame spread region.

\section{ACKNOWLEDGMENT}

The authors would like to express their sincere thanks to Messxs. M. okada, N. Takahashi, T. Sakurai and R. Tanabe for their help in conducting experiments. 


\section{REFERENCES}

1. Kaptein, M. and Hermance, C. E., "Horizontal propagation of Laminar Flames through Vertically Diffusing Mixtures above a Ground Plane," Sixteenth Symposium (International) on Combustion, pp. 1295-1306, The Combustion Institute, 1976.

2. Takeno, K. and Hirano, T., "Flame spread over porous solids soaked with a Combustible Liquid," Twenty-first symposium (International) on Combustion, The Combustion Institute, 1986.

3. Feng, C. C., Lam, S. H. and Glassman, I., "Flame Propagation through Layered Fuel-Air Mixtures," Combustion Science and Technology, 10, $57-71,1975$.

4. Glassman, I. and Dryer, F. L., "Flame Spreading Across Liquid Fuels," Fire Safety J., 3, 123-138, 1980.

5. Hixano, T., Suzuki, T., Mashiko, I. and Tanabe, N., "Gas Movements in Front of Flames Propagating Across Methanol," Combustion Science and Technology, 22, 83-91, 1980.

6. Hirano, T. and Suzuki, T., "Theoretical Simulation of Gas Movements in Front of Propagating Flames Through Layered Flammable Mixtures," Combustion Science and Technology, 23, 215-224, 1980.

7. Suzuki, T. and Hirano, T., "Flame Propagation across a Liquid Fuel in an Aix stream," Nineteenth symposium (International) on Combustion, pp. 877-884, The Combustion Institute, 1982.

8. Hirano, T., Suzuki, T., Sato, J. and Ohtani, H., "Flame Spread over crude oil sludge," Twentieth symposium (International) on combustion, pp. 1611-1617, The Combustion Institute, 1984.

9. Suzuki, T., Kudo, N., Sato, J., Ohtani, H. and Hirano, T., "Flame Spread over Thin Layers of Crude oil sludge," Fire Safety Science, Proceedings of the First International symposium, pp. 55-64, Hemisphere, 1986.

10. Takeno, k. and Hirano, T., Proceedings of Japanese Association of Fixe Science and Engineering, p. 105, 1987, (in Japanese).

11. Fernandez-pe110, A. C. and Hirano, T., "Controlling Mechanisms of Flame Spread," Combustion Science and Technology, 32, 1, 1983.

12. Hirano, T. and Kanno, Y., "Aerodynamic and Thermal structures of the Laminar Boundary Layer over a Flat Plate with a Diffusion Flame," Fourteenth Symposium (International) on Combustion, pp. 391-398, The Combustion Institute, 1973.

13. Hirano, T. and Sato, K., "Effects of Radiation and Convection on Gas Velocity and Temperature profiles of Flames spreading over Paper," Fifteenth Symposium (International) on Combustion, pp. 233-241, The Combustion Institute, 1974. 